\title{
Low birth weight and risk of high blood pressure in adulthood
}

\author{
GERHARD GENNSER， PER RYMARK， PER ERIK ISBERG
}

\begin{abstract}
Hospital birth records were sought for 104 men from a pool of male army conscripts with "normal" or "high" blood pressure when measured at 28 years of age. Of 77 men whose birth weight and date of the mother's last menstrual period before the pregnancy could be found, 25 had a resting diastolic blood pressure of $\geqslant 90 \mathrm{~mm} \mathrm{Hg}$. In 11 of these compared with nine of the 52 men with normal diastolic pressures their birth weights in relation to gestational age had been below the mean and 1 SD of a comparable Swedish population. The risk of increased diastolic blood pressure in early adult life was significantly higher among men who had been growth retarded at birth than among those whose birth weight had been appropriate for gestational age (odds ratio $3.63 ; 95 \%$ confidence interval 1.14 to 12.57 ).

Being born small for gestational age may be a predictor of raised blood pressure in early adult life.
\end{abstract}

\section{Introduction}

The finding that high blood pressure runs in families ${ }^{1}$ suggests that hypertension is an inherited disorder. The familial pattern of high blood pressure has been recorded from the first week of life up to adulthood..$^{1-3}$ Though the pathogenesis underlying established hypertension is unknown, there is evidence that both genetic and environmental factors interact in susceptible people. ${ }^{45}$ Hypertension of pregnancy, irrespective of definition, has also been shown to have a very strong familial association. ${ }^{67}$ With a view to identifying people at risk of developing high blood pressure later in life we focused attention on those who had been small for gestational age at birth. Thus in fetuses with retarded growth Doppler ultrasound has shown evidence of increased peripheral resistance to flow in the descending aorta ${ }^{8}$ We thought it important to elucidate whether people with a history of growth retardation in the fetal period, irrespective of cause, are prone to high blood pressure as adults. To this end young men were studied at an age when the known effects of growth and maturation on blood pressure have subsided ${ }^{9}$ and the incidence of hypertension due to vascular degeneration has not begun to rise.

\section{Subjects and methods}

From the National Institute for Psychosocial Factors and Health, Stockholm, we obtained the national insurance numbers of 104 men randomly selected from a pool of "hypertensive" and "normotensive" male army conscripts in the Greater Stockholm area. The pool had been collected by the institute for our study and was therefore not representative of all male Swedish conscripts. The men's blood pressures had been checked during medical examinations at 28 years of age, and 32 had been noted as having a diastolic pressure of $90 \mathrm{~mm} \mathrm{Hg}$ or more. By means of the national insurance numbers and the National Population Registry conscripts' records were located at the relevant maternity units and information on birth weight and

Department of Obstetrics and Gynaecology, University of Lund, Malmö General Hospital, S-214 01 Malmö, Sweden

GERHARD GENNSER, MD, PHD, associate professor

PER RYMARK, MD, house obstetrician

Department of Statistics, University of Lund, S-221 00 Lund, Sweden PER ERIK ISBERG, $M A$, research officer

Correspondence to: Dr Gennser. date of the mother's last menstrual period before the pregnancy obtained for 77. The remaining 27 conscripts were excluded from the study owing to their records being unavailable or lacking the relevant data. Twenty five conscripts in the study group had increased diastolic blood pressure as compared with seven of those excluded. To avoid bias data on blood pressure were withheld from the investigators until the final statistical evaluation.

Gestational age at birth was estimated from the first day of the last menstrual period before the pregnancy. A third degree polynomial of the mean fetal weight for gestational age of a comparable Swedish population ${ }^{10}$ was used to calculate individual deviations in birth weight from the expected mean value for age (expressed as a percentage). The range of birth weights in the reference population was proportional to the mean weight, one standard deviation being $11 \%$ of the mean. ${ }^{10}$ On the basis of deviations in birth weight the study group was divided into six subgroups: group $1, \geqslant+22 \%$; group 2 , $+11-21 \%$; group $3,0-+10 \%$; group $4,-1-10 \%$; group $5,-11-21 \%$; group 6 , $\leqslant-22 \%$.

Blood pressure was measured with a mercury sphygmomanometer in 72 conscripts (after 60 minutes' recumbency) and with an aneroid sphygmomanometer in the remaining five (after 10 minutes' recumbency). Blood pressure was recorded on two consecutive days in all subjects, the value obtained under the most basal conditions being used for the study. Based on earlier blood pressure studies in pools of male conscripts ${ }^{11}$ "high" diastolic blood pressure was defined as $90 \mathrm{~mm} \mathrm{Hg}$ or more.

The risk of high diastolic blood pressure in adult life in relation to a history of low birth weight for gestational age $(\leqslant-11 \%)$ was evaluated by calculating the odds ratio as described by Fleiss. ${ }^{12}$ This method was also used for the risks of increased systolic pressure $(\geqslant 145 \mathrm{~mm} \mathrm{Hg})$ and high mean arterial pressure ( $\geqslant 110 \mathrm{~mm} \mathrm{Hg}$ ) in adulthood and for the risks of high diastolic blood pressure in adulthood in relation to a low absolute birth weight $(\leqslant 2500 \mathrm{~g})$ and low absolute gestational age at birth $(\leqslant 37$ weeks and $\leqslant 38$ weeks).

\section{Results}

Of the 77 conscripts, 25 had a diastolic blood pressure of $90 \mathrm{~mm} \mathrm{Hg}$ or higher at 28 years of age. The distribution of these men among the birth weight deviation groups was skewed towards a birth weight below the mean and 1 SD (table I). The odds ratio for risk of subsequent high blood pressure among men with a history of low birth weight for gestational age ( $\leqslant-11 \%$ ) was $3.63(95 \%$ confidence interval 1.14 to 12.57 ) (table II).

Analysis of the odds ratios for the relation between low birth weight on the one hand and subsequent systolic, diastolic, and mean arterial pressures on the other showed high diastolic pressure in adulthood to have the strongest relation followed by high mean arterial pressure (table II). The risk of high diastolic pressure was also significantly increased for men with a low absolute birth weight (table III) and low absolute gestational age at birth (table IV).

\section{Discussion}

The cut off value ( $\geqslant 90 \mathrm{~mm} \mathrm{Hg}$ ) defining high diastolic blood pressure was adopted because it had been used in earlier studies on the same subjects ${ }^{11}$ and represented the mean and 2 SD of diastolic

TABLE I-Deviations in birth weight among male army conscripts with normal and high $(\geqslant 90 \mathrm{~mm} \mathrm{Hg}$ ) diastolic blood pressures

\begin{tabular}{lcccccccc}
\hline & \multicolumn{7}{c}{ Birth weight deviation group } \\
\cline { 2 - 7 } $\begin{array}{c}\text { Diastolic } \\
\text { pressure }\end{array}$ & $\begin{array}{c}1 \\
(\geqslant+22 \%)\end{array}$ & $\begin{array}{c}2 \\
(+11-21 \%)\end{array}$ & $\begin{array}{c}3 \\
(0-+10 \%)\end{array}$ & $\begin{array}{c}4 \\
(-1-10 \%)\end{array}$ & $\begin{array}{c}5 \\
(-11-21 \%)\end{array}$ & $\begin{array}{c}6 \\
(\leqslant-22 \%)\end{array}$ & Total \\
\hline$\geqslant 90 \mathrm{~mm} \mathrm{Hg}$ & 3 & 3 & 6 & 2 & 8 & 3 & 25 \\
$<90 \mathrm{~mm} \mathrm{Hg}$ & 4 & 7 & 13 & 19 & 9 & 0 & 52 \\
\hline Total & 7 & 10 & 19 & 21 & 17 & 3 & 77
\end{tabular}

$\star$ Deviation calculated as percentage difference from expected mean value for age (see text). 
TABLE II-Men with normal and high blood pressures and mean arterial pressures stratified by presence and absence of history of low birth weight for gestational age

\begin{tabular}{|c|c|c|c|c|c|c|c|c|c|}
\hline \multirow[b]{2}{*}{ Low birth weight } & \multicolumn{3}{|c|}{ Diastolic pressure } & \multicolumn{3}{|c|}{ Systolic pressure } & \multicolumn{3}{|c|}{ Mean arterial pressure } \\
\hline & $\geqslant 90 \mathrm{~mm} \mathrm{Hg}$ & $<90 \mathrm{~mm} \mathrm{Hg}$ & Total & $\geqslant 145 \mathrm{~mm} \mathrm{Hg}$ & $<145 \mathrm{~mm} \mathrm{Hg}$ & Total & $\geqslant 110 \mathrm{~mm} \mathrm{Hg}$ & $<110 \mathrm{~mm} \mathrm{Hg}$ & Total \\
\hline $\begin{array}{l}\text { Present } \\
\text { Absent }\end{array}$ & $\begin{array}{l}11^{\star} \\
14\end{array}$ & $\begin{array}{r}9 \\
43\end{array}$ & $\begin{array}{l}20 \\
57\end{array}$ & $\begin{array}{c}6 \dagger \\
10\end{array}$ & $\begin{array}{l}14 \\
47\end{array}$ & $\begin{array}{l}20 \\
57\end{array}$ & $\begin{array}{c}8 \ddagger \\
10\end{array}$ & $\begin{array}{l}12 \\
47\end{array}$ & $\begin{array}{l}20 \\
57\end{array}$ \\
\hline Total & 25 & 52 & 77 & 16 & 61 & 77 & 18 & 59 & 77 \\
\hline
\end{tabular}

*Odds ratio $3.63(95 \%$ confidence interval $1 \cdot 14$ to $12 \cdot 57)$.

Odds ratio 2.03 (95\% confidence interval 0.53 to 7.54$)$.

fOdds ratio 3.08 ( $95 \%$ confidence interval 0.89 to $11 \cdot 20$ ).

TABLE III-Absolute birth weights of conscripts and diastolic blood pressures in adulthood

\begin{tabular}{cccc}
\hline & \multicolumn{3}{c}{ Diastolic pressure } \\
\cline { 2 - 4 } $\begin{array}{c}\text { Birth weight } \\
\text { g })\end{array}$ & $\geqslant 90 \mathrm{~mm} \mathrm{Hg}$ & $<90 \mathrm{~mm} \mathrm{Hg}$ & Total \\
\hline$\leqslant 2500$ & $4^{\star}$ & 0 & 4 \\
$>2500$ & 21 & 52 & 73 \\
\hline Total & 25 & 52 & 77 \\
\hline
\end{tabular}

${ }^{\star}$ Odds ratio $21 \cdot 98(95 \%$ confidence interval $1 \cdot 46$ to $101 \cdot 17)$.

TABLE IV-Absolute gestational ages of conscripts and diastolic blood pressures in adulthood

\begin{tabular}{|c|c|c|c|}
\hline \multirow[b]{2}{*}{ Gestational age (completed weeks) } & \multicolumn{3}{|c|}{ Diastolic pressure } \\
\hline & $\geqslant 90 \mathrm{~mm} \mathrm{Hg}$ & $<90 \mathrm{~mm} \mathrm{Hg}$ & Total \\
\hline $\begin{array}{l}\leqslant 37 \\
>37\end{array}$ & $24^{1^{\star}}$ & $\begin{array}{r}1 \\
51\end{array}$ & $\begin{array}{r}2 \\
75\end{array}$ \\
\hline Total & 25 & 52 & 77 \\
\hline $\begin{array}{l}\leqslant 38 \\
>38\end{array}$ & $\begin{array}{l}9+ \\
16\end{array}$ & $\begin{array}{r}8 \\
44\end{array}$ & $\begin{array}{l}17 \\
60\end{array}$ \\
\hline Total & 25 & 52 & 77 \\
\hline
\end{tabular}

*Odds ratio $2 \cdot 10$ ( $95 \%$ confidence interval 0.05 to $81 \cdot 99)$.

tOdds ratio 3.01 ( $95 \%$ confidence interval 0.89 to $10 \cdot 87$ ).

blood pressure in a Swedish population of 28 year old men. ${ }^{13}$ Systolic pressure was disregarded in our series because several men with high diastolic pressures had a systolic pressure below $145 \mathrm{~mm} \mathrm{Hg}$. In retrospect odds ratios showed the cut off value for high diastolic blood pressure to be adequate for defining a risk group.

Though the relation between low birth weight and subsequent high diastolic blood pressure appears not to have been reported, several studies have examined the relation between hypertension in pregnant women and high blood pressure in their offspring. Increased blood pressure during childhood has been noted in daughters but not sons of pre-eclamptic mothers ${ }^{14}$; this finding was not confirmed in a later study of children of roughly the same age. ${ }^{15}$ Children aged 3-6 years and born to mothers with hypertension in their first pregnancy had higher blood pressures than children born after a normotensive pregnancy. ${ }^{16}$ Moreover, children of mothers whose blood pressures remained high after a hypertensive pregnancy had a higher average blood pressure than children of women whose blood pressures returned to normal after pregnancy. ${ }^{\text {is }}$ Both groups of children had higher blood pressures than children with a history of normotensive gestation. ${ }^{15}$ The disparity among reports on clustering of hypertensive disorders in families suggests that several hypertensive syndromes occur. Thus true eclampsia is apparently not associated with an increased incidence of hypertension in the non-pregnant state as compared with control populations, ${ }^{17}$ but there is a strong risk of cases of pre-eclampsia occurring in the families of women with a history of eclampsia in their first pregnancy. ${ }^{\text {? }}$

Data on maternal blood pressure were not collected in this study.
Hence the possibility exists that intrauterine growth retardation in these conscripts was associated with maternal hypertension and that the high blood pressure at 28 years of age was an expression of hereditary or familial hypertensive disorder rather than the result of growth retardation itself. Nevertheless, as in only a third of cases of intrauterine growth retardation is there a history of pre-eclampsia and related disorders ${ }^{18}$ it seems reasonable to assume that only a minority of our cases of high diastolic pressure were associated with maternal hypertension. The relation between retarded fetal growth and increased adult blood pressure may also be due to environmental factors, the nature of which is unknown. Doppler ultrasound measurements of blood velocity waveforms show intrauterine growth retardation to be accompanied by reduced or abolished forward flow velocities in the fetal aorta ${ }^{8}$ and umbilical arteries $^{19}$ at end diastole, indicating increased total peripheral resistance to blood flow instead of the physiological decrease that normally occurs with advancing gestation. ${ }^{20}$ These findings have been substantiated by histological evidence of reduced placental vasculature in growth retarded cases. ${ }^{21}$ Increased pressure in the systemic fetal circulation as a mechanism for maintaining placental perfusion is suggested by increased pulse wave velocity in the aorta of growth retarded fetuses as compared with fetuses of normal growth. ${ }^{22}$ Possibly if increased pressure in the fetal circulation occurs at a vulnerable stage of development it might adjust the blood pressure regulating system to a higher than normal set point, thereby inducing the postnatal circulatory system to work at increased pressure. Conceivably, restriction of placental blood flow, rather than any genetic signal, may be responsible for high blood pressure in the offspring.

This retrospective pilot study was disadvantaged by being based on subjects born before the era of ultrasound scanning to assess early gestational age. Nevertheless, the data suggest that people born small for gestational age are at risk of high blood pressure in early adult life and that intrauterine growth retardation may be an important predictor of subsequent hypertensive disorder. Whatever the mechanism responsible for hypertension, these findings, though requiring confirmation, suggest an important late effect of being born small for gestational age.

We thank Professor $T$ Theorell for the national insurance numbers and blood pressure data of the conscripts. The study was supported by grants from the Greta and Johan Kock Foundation and from the Swedish League Against Hypertension.

\section{References}

1 Zinner SH, Levy PS, Kass EH. Familial aggregation of blood pressure in childhood. $N$ Engl f Med 1971;281:401-4.

2 Biron P, Mongeau J-G. Familial aggregation of blood pressure and its components. Pediatr Clin North Am 1978;25:29-33.

3 Havlik RJ, Garrison RJ, Feinleb M, Kannel WB, Castelli WP, McNamara DM. Blood pressure aggregation in families. Am $\mathcal{J}$ Epidemiol 1979;110:304-12.

4 Miall WE, Oldham PD. The hereditary factor in arterial blood pressure. Br Med f 1963;i:75-80. Bengtsson B, Thulin T, Scherstén B. Familial resemblance in casual blood pressure-a maternal effect? Clin Sci 1979;57:279-81.

6 Chesley LC, Cosgrove RA, Annitto JE. Pregnancy in the sisters and daughters of eclamptic women. Pathologia et Microbiologia 1961;24:662-6.

7 Chesley LC, Cooper DW. Genetics of hypertension in pregnancy: possible single gene control of pre-eclampsia and eclampsia in the descendants of eclamptic women. Br $\mathcal{J}$ Obstet Gynaecol 1986;93:898-908.

8 Griffin D, Cohen-Overbeek T, Campbell S. Fetal and uteroplacental blood flow. Clin Obstet Gynecol 1983;10:565-602.

9 Lauer RM, Anderson AR, Beaglehole R, et al. Factors related to tracking of blood pressure in 
children. US National Center for Health Statistics health examination surveys, cycles II and III. Hypertension 1984;6:307-14

10 Persson PH, Weldner B-M. Intra-uterine weight curves obtained by ultrasound. Acta Obstet Gynecol Scand 1986;65:169-74.

11 Theorell T, Knox S, Svensson J, et al. Blood pressure variations during a working day at age 28 effects of different types of work and blood pressure level at age 18. 7 Human Stress 1985;11: 36-41.

12 Fleiss JL. Statistical methods for rates and proportion. 2nd ed. New York: John Wiley, 1973:212-25.

13 Thulin T, Bengtsson B, Scherstén B. Assessment of casual blood pressure variations. Postgrad Med f 1978;54:10-5.

14 Langford H, Watson RL. Prepregnant blood pressure, hypertension during pregnancy, and later blood pressure of mothers and offspring. Hypertension 1980;2(suppl 1):130-3.

15 Svensson A, Sigström L, Andersch B, et al. Low erythrocyte $\mathrm{Na}^{+} / \mathrm{K}^{+}$ratio in children with mild blood pressure elevation and a positive family history of hypertension. Foumal of Hypertension 1984;2(suppl 3):473-5.

16 Kotchen JM, Kotchen TA, Cottrill CM, Guthrie GP Jr, Somes G. Blood pressure of young mothers and their first children 3-6 years following hypertension during pregnancy. $f$ Chronic Dis 1979;32:653-9.

17 Chesley L, Cosgrove S, Annito J. A follow-up study of eclamptic women: fourth periodic report. Am f Obstet Gynecol 1962;83:1360-72.

18 Keirse MJNC. Epidemiology and aetiology of the growth retarded baby. Clin Obstet Gynaecol 1984;11:415-36.

19 Trudinger BJ, Giles WB, Cook MC, Bambardieri J, Collins L. Fetal umbilical artery flow velocity waveforms and placental resistance: clinical significance. Brf Obstet Gynaecol 1985;92:23-30.

20 Dawes GS. Foetal and neonatal physiology. Chicago: Year Book Medical Publishers, 1968:68-72.

21 Giles WB, Trudinger BJ, Baird PJ. Fetal umbilical artery flow velocity waveforms and placental resistance: pathological correlation. Br 7 Obstet Gynaecol 1985;92:31-8.

22 Gennser G, Vetter K, Sindberg Eriksen P, Huch R, Huch A. Ultrasonic evidence for altered pulsatile dynamics in the aorta of growth retarded fetuses. Clinical and Experimental Hypertension 1984;3:300.

Accepted 2 February 1988

\title{
Alcohol consumption in Dundee primigravidas and its effects on outcome of pregnancy
}

\author{
NABEEL D SULAIMAN，C DU V FLOREY，D J TAYLOR，S A OGSTON
}

\begin{abstract}
In a population based cohort study information on the consumption of alcohol was obtained from $95 \%$ of the 952 consecutive primigravidas who lived in the Dundee district and attended for antenatal care between May 1985 and April 1986. Before realising that they were pregnant more than $90 \%$ drank alcohol and $53 \%$ were cigarette smokers. During the first four months of pregnancy, however, the proportion of women drinking and smoking fell to $56 \%$ and $44 \%$, respectively. Alcohol consumption of more than $120 \mathrm{~g}$ absolute alcohol/week (12 or more standard drinks) during pregnancy was related to shorter gestational age $\mathbf{( - 2 . 6}$ weeks), smaller head circumference $(-18 \mathrm{~mm})$, shorter $(-21$ $\mathrm{mm})$ and lighter $(-499 \mathrm{~g})$ babies, and lower Apgar scores at five minutes $(-0.4$, all $p<0.01)$. After adjustment for the effect of smoking, social class, mother's size, and other confounding factors, however, an alcohol intake of more than $120 \mathrm{~g} /$ week was significantly related only to shorter gestational age $(-2.0$ weeks, $\mathbf{p}<0.001)$ and lower Apgar score at five minutes $(-0.2, \mathbf{p}<0.05)$. Alcohol intake in the region of $100-119 \mathrm{~g} /$ week was significantly related to smaller head circumference $(-12 \mathrm{~mm}, p<0.05)$. Analysis by type of beverage consumed suggested that beer rather than wine or spirits was associated with a poorer outcome.

As there was no detectable effect on pregnancy of alcohol consumption below $100 \mathrm{~g} /$ week, it is suggested that health education should be directed towards mothers who drink more than this amount.
\end{abstract}

\section{Introduction}

Interest in the effects of maternal alcohol consumption on the fetus has grown since the publication of a description of the morphological

Ninewells Hospital and Medical School, Dundee DD1 9SY

NABEEL D SULAIMAN, MB, MPH, PhD candidate, department of community medicine

C DU V FLOREY, MD, FFCM, professor, department of community medicine

D J TAYLOR, MD, MRCOG, senior lecturer and honorary consultant, department of obstetrics and gynaecology

S A OGSTON, MA, MSC, lecturer in statistics, department of community medicine

Correspondence to: Dr Sulaiman. features of the fetal alcohol syndrome. ${ }^{1}$ These features include growth retardation, mental retardation, and a characteristic facial appearance, in addition to systemic anomalies. There now seems to be little doubt that excessive drinking throughout pregnancy gives rise to the fetal alcohol syndrome in some women's offspring. The question of how much social or moderate drinking is safe, however, has yet to be answered satisfactorily. Some studies have shown fairly low consumption to have adverse effects on birth weight, ${ }^{2-4}$ spontaneous abortion, ${ }^{56}$ stillbirths, ${ }^{7}$ and neonatal behaviour, ${ }^{8}$ whereas others, in different populations and with different techniques, have found no important effect. ${ }^{10}$ The overall conclusion from these studies is that the effect of a mother's social drinking during pregnancy on her offspring is at most limited.

This study's main aim was to estimate the level of alcohol consumption at which an adverse effect on the outcome of pregnancy is detectable. We investigated the effect of different levels of alcohol consumption both before and during pregnancy on various outcome measures in a cohort of primigravidas.

\section{Subjects and methods}

The sample consisted of all primigravidas living in Dundee district whose first antenatal visit fell between 1 May 1985 and 30 April 1986. Dundee is served by only three antenatal clinics, and all women are delivered in this hospital. The sample was thus determined by the population, with no appreciable private obstetric care or cross boundary flow to other care systems.

The size of the sample was estimated, based on the expected differences in birth weight between the offspring of abstainers and those of drinkers Assuming a 1:4 ratio of the size of these two groups, a sample size of 800 would allow a true difference of $100 \mathrm{~g}$ at the $5 \%$ level of significance to be detected with $80 \%$ power.

The mothers were informed of the nature of the study and invited to take part at their first antenatal visit. For organisational reasons the mothers were interviewed at their next visit (commonly at 16 weeks) to obtain demographic data and a history of beverage consumption and tobacco smoking before and during pregnancy. The questions about alcohol were included among those about coffee, tea, and soft drinks. An aliquot of blood was included in the usual antenatal blood collection and used to estimate blood alcohol concentration, $\gamma$-glutamyltransferase activity, and plasma thiocyanate concentration (a measure of beer drinking as well as of cigarette smoking). The questions included the quantity, frequency, and variability items from the questionnaires of Jessor $e t a l,{ }^{11}$ Cahalan $e t a l,{ }^{12}$ and A P Streissguth (personal communication). The answers were later converted to the average amount of absolute alcohol in $\mathrm{g}$ consumed daily $(1 \mathrm{ml}$ absolute alcohol $=0.8 \mathrm{~g}$; one standard drink $\approx 10 \mathrm{~g}$ absolute alcohol). Binge 